\title{
Microstructures and Mechanical Properties of 7Mn Steel Manufactured by Different Rolling Processes
}

\author{
Bin $\mathrm{Hu}^{1}$ iD and Haiwen Luo ${ }^{1,2, *}$ \\ 1 School of Metallurgical and Ecological Engineering, University of Science and Technology Beijing, \\ Xue Yuan Lu 30, Beijing 100083, China; hubin19880410@163.com \\ 2 Central Iron and Steel Research Institute, Xue Yuan Nan Lu 30, Beijing 100081, China \\ * Correspondence: luohaiwen@ustb.edu.cn; Tel.: +86-10-6233-2911
}

Received: 28 September 2017; Accepted: 27 October 2017; Published: 1 November 2017

\begin{abstract}
We investigated both the microstructures and tensile properties of 7Mn steel, which was either hot-rolled, warm-rolled or cold-rolled before intercritical annealing at $700{ }^{\circ} \mathrm{C}$ for $5 \mathrm{~h}$. It can be concluded that the warm-rolled and annealed microstructures are a kind of mixture of hot rolled and cold rolled ones. They are composed of ferrite and retained austenite, the latter having a wide size distribution and two types of morphologies: equiaxed and lamellar. These retained austenite grains are expected to transform to martensite in a more sustainable way-the warm-rolled and annealed steel exhibits the best combination of ultimate tensile strength and total elongation among the three studied steels and a shorter yield point elongation than the cold-rolled one.
\end{abstract}

Keywords: cold rolling; warm rolling; hot rolling; microstructure; tensile properties; medium Mn steel

\section{Introduction}

Recently, a new class of transformation induced plasticity (TRIP) steels containing 5-10 wt \% Mn have received a wide attention because they exhibit an excellent combination of ultimate tensile strength (UTS) and total elongation (TE) owing to the presence of stable austenite in the matrix. The usual manufacturing process of these steels is the cold rolling process followed by intercritical annealing (IA), during which a part of the initial martensite or ferrite grains shall transform to austenite grains so that they can be retained afterwards at ambient temperature for the TRIP-assisted effect during deformation [1,2]. Previous researches on the medium-Mn steels mostly focused on the influences of compositions and IA processes on the microstructures and mechanical properties of medium-Mn TRIP steels [3-10]. For examples, Dong et al. have developed a 5Mn dual-phased steel (all alloy compositions are in $\mathrm{wt} \%$, unless otherwise mentioned) where the product of the UTS and the TE is greater than $30 \mathrm{GPa} \%$ [3-7] after a relatively long IA. Gibbs et al. [8] developed a 0.1C-7Mn steel with an UTS of $1376 \mathrm{MPa}$ and a TE of $9 \%$. They suggested that the retained austenite (RA) was not stable enough to overcome necking during high strain when the IA temperature is too high. Aydin et al. [9] developed a $0.2 \mathrm{C}-10 \mathrm{Mn}-3 \mathrm{Si}-3 \mathrm{Al}$ steel, which also had a dual-phased microstructure (ferrite and austenite) and exhibited the UTS value of more than $900 \mathrm{MPa}$ and TE of $23 \%$. Moreover, they found that both TE and UTS increased when a larger fraction of RA transformed to martensite during the tensile deformation. Suh et al. [10] investigated the effect of Al content on the tensile properties of both $6 \mathrm{Mn}-0.12 \mathrm{C}-3 \mathrm{Al}$ and $5 \mathrm{Mn}-0.12 \mathrm{C}-1 \mathrm{Al}$ steels, and found that higher $\mathrm{Al}$ content could lead to greater elongation but lower UTS after a short IA. The best combination of strength and plasticity was achieved in the steel containing higher Al content, for which, the values of TE, UTS and yield strength (YS) were $28.6 \%, 994 \mathrm{MPa}$ and $774 \mathrm{MPa}$, respectively. In addition, the initial microstructure before IA could also affect the morphology and fraction of RA and then the tensile properties of medium-Mn TRIP steels. Han et al. [11] reported that the cold and hot rolled microstructures before IA transformed to the 
ferrite-austenite duplex structure in the equiaxed and lamellar morphologies during IA, respectively. As a result, the hot rolled sheet had the lower YS and UTS but larger TE in comparison with the cold rolled sheet; Luo [12] has proposed that the carbide particles, which have precipitated before IA, can either positively or negatively influence the fraction of RA formed in the 5Mn TRIP steel during IA, depending on whether they dissolve. Moreover, the dissolution kinetics of carbide strongly depends on the relative Mn enrichment in carbide in comparison with the Mn content of austenite.

Different from the popular manufacturing processes like hot and cold rolling, the warm rolling process has been recently employed to manufacture the medium-Mn steels and it has demonstrated the great potential to achieve the excellent combination of UTS and TE [13,14]. In this paper, the microstructures after the hot, warm or cold rolling and the subsequent annealing process were examined. The influence of different rolling processes on the final microstructures and tensile properties were then discussed.

\section{Materials and Experimental Methods}

The composition of studied steel is $0.25 \mathrm{C}-7.17 \mathrm{Mn}-2.6 \mathrm{Al}$ in weight percentage. Thermodynamic calculations were made using Thermal-Calc 2017a and TCFE9 database, which are products of Thermo-Calc Software Company located in Stockholm, Sweden. The calculation results indicate that the temperatures for the ferrite and cementite phases to completely disappear are $863{ }^{\circ} \mathrm{C}$ and $665{ }^{\circ} \mathrm{C}$ respectively. Austenite and ferrite phase fractions are both $50 \%$ at $700{ }^{\circ} \mathrm{C}$, see Figure 1 . These values are important for designing the hot rolling and intercritical annealing processes [15].
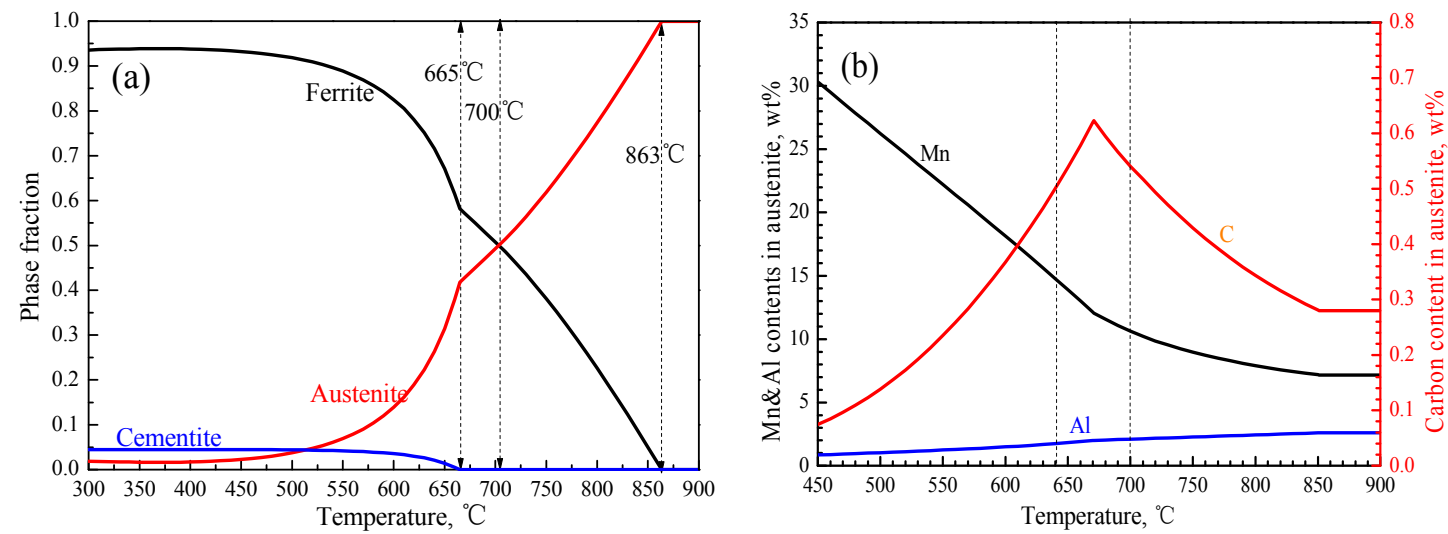

Figure 1. Equilibrium phase fractions (a) and compositions of austenitic phase (b) in the studied 7Mn steel at different temperatures calculated using ThermoCalc 2017 and TCFe 9 database.

The studied steel was melted in $50 \mathrm{~kg}$ vacuum induction furnace and cast into ingot, which was then hot forged into $40 \mathrm{~mm}$-thick plates. The plates were heated to $1050{ }^{\circ} \mathrm{C}$ and isothermally held for $2.5 \mathrm{~h}$ for homogenization, and then hot rolled to $4 \mathrm{~mm}$-thickness after 5 passes with the finish temperature about $800{ }^{\circ} \mathrm{C}$ in a pilot hot rolling mill, followed by water cooling to room temperature, see Figure $2 \mathrm{a}$. The hot rolled sheets were then intercritically annealed at $700{ }^{\circ} \mathrm{C}$ for $1 \mathrm{~h}$ before they were subjected to cold rolling to a thickness of $2 \mathrm{~mm}$ in a four-high cold rolling mill, see Figure $2 \mathrm{~b}$. In addition, a novel warm rolling process was employed. In this case, the $4 \mathrm{~mm}$-thick hot rolled steel sheet was firstly heated to $600{ }^{\circ} \mathrm{C}$ and isothermally held for $10 \mathrm{~min}$ in a box furnace, and then taken out and rolled to $3 \mathrm{~mm}$ in three passes; due to the rapid decrease of temperature during the warm rolling, the steel was then heated again to $600{ }^{\circ} \mathrm{C}$ for the same period isothermal holding, followed by the same warm rolling process in three passes until the final thickness of $2 \mathrm{~mm}$, which is shown in Figure 2c. All the rolled $7 \mathrm{Mn}$ steel sheets were finally annealed at $700{ }^{\circ} \mathrm{C}$ for $5 \mathrm{~h}$ and then cooled to room temperature in air. 

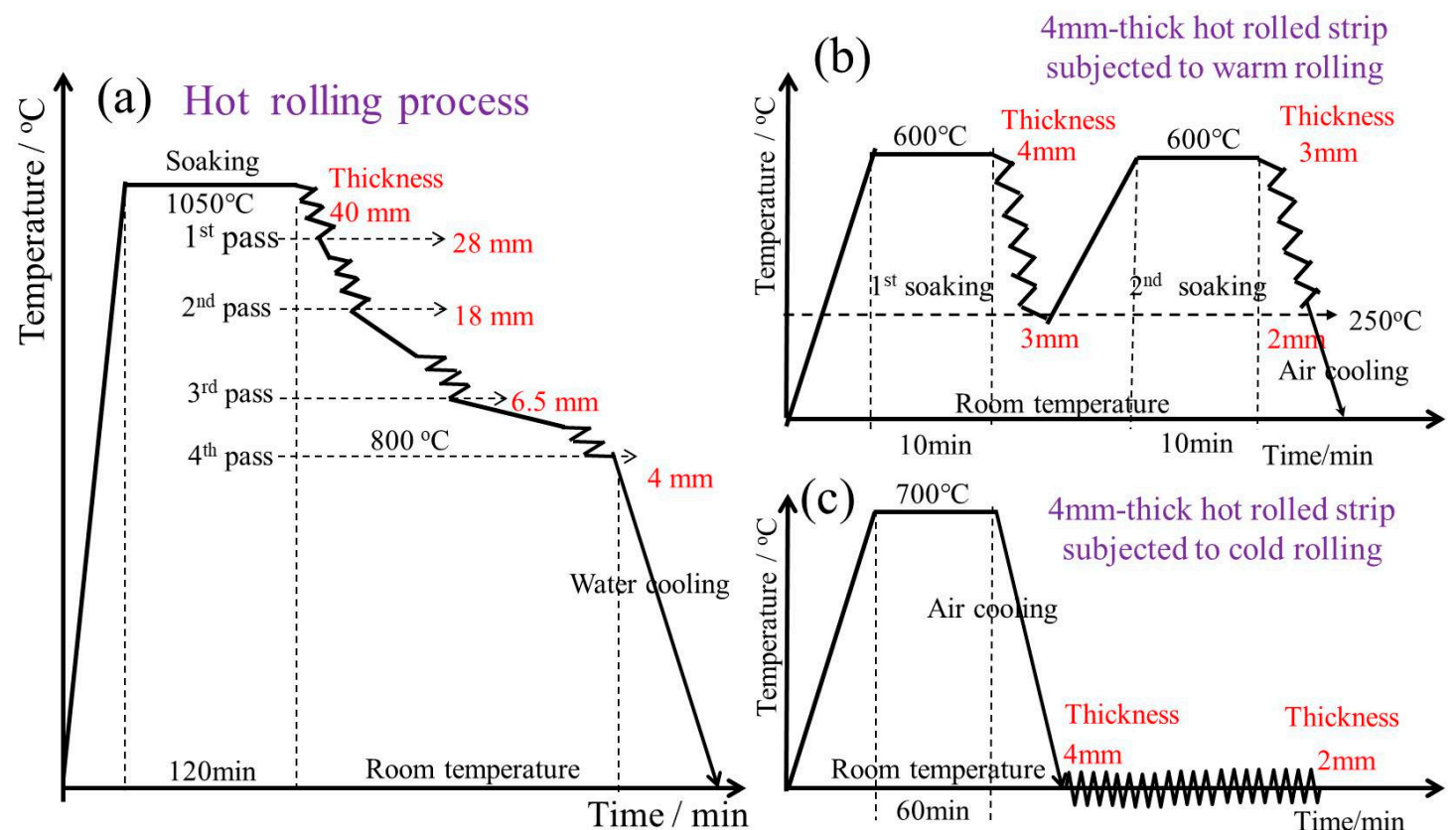

Figure 2. The illustrations of hot rolling (a), warm rolling after hot rolling (b) and the cold rolling after hot rolling processes (c).

The tensile samples were machined from the annealed sheets along the rolling direction with the gauge length and width of $50 \mathrm{~mm}$ and $12.5 \mathrm{~mm}$ respectively. Uniaxial tensile tests were carried out at the speed of $2 \mathrm{~mm} / \mathrm{min}$ on the WDW-200D tensile testing machine. The microstructures of the samples were examined by field emission scanning electron microscope (FE-SEM), JSM-6710F (JEOL in Tokyo, Japan) after polishing and etching in $4 \%$ nitric acid for $20 \mathrm{~s}$. Microstructures were examined using both transmission electron microscope (TEM), TecnaiF30 (FEI in Hillsboro, OR, USA) performed at $300 \mathrm{kV}$ and Auger Nano probe combined with Electron Backscatter Diffraction (Auger-Nano/EBSD), PHI 710 (ULVAC-PHI, INC in Chigasaki, Japan) performed at $20 \mathrm{kV}$. EBSD examination was performed on the rolling surface of sheet. The mapping was performed in the area of $14 \times 14 \mu \mathrm{m}$ or $7 \times 7 \mu \mathrm{m}$ with the step size of $0.04 \mu \mathrm{m}$. The EBSD data was finally processed using the OIM 7.3 software (EDAX in Mahwah, NJ, USA). Thin foils for TEM examinations were prepared by the mechanical polishing to about $20 \mu \mathrm{m}$ thickness and the final twin-jet polishing in a solution of 5\% perchloric acid and $95 \%$ ethanol at around $-20{ }^{\circ} \mathrm{C}$. Samples for EBSD and X-ray diffraction (XRD) examination by DMAX-RB (Rigaku in Tokyo, Japan) were electrolytically polished in a solution of $20 \%$ perchloric acid and $80 \%$ ethanol at room temperature. The volume fractions of retained austenite (RA) were calculated from the XRD measurements using $\mathrm{Cu}-\mathrm{K} \alpha$ radiation on the basis of integrated intensities of the $(200) \alpha,(211) \alpha$, (200) $\gamma,(220) \gamma$ and (311) $\gamma$ diffraction peaks. The average $C$ content of RA grains can be estimated by the measured lattice parameters and the compositions of austenite grains using the following equation [16,17]:

$$
\alpha_{\gamma}=3.578+0.0453 x_{\mathrm{C}}+0.00095 x_{\mathrm{Mn}}+0.0033 x_{\mathrm{Al}}
$$

where $x_{\mathrm{C}}, x_{\mathrm{Mn}}$ and $x_{\mathrm{Al}}$ are the mass fractions of $\mathrm{C}, \mathrm{Mn}$ and $\mathrm{Al}$ in austenite respectively; $\alpha_{\gamma}$ is the average lattice parameter of austenite grains, which can be calculated from the XRD measurement. Because the lattice parameters of austenite depend on the concentrations of interstitial atoms more than those of substitutional atoms, we assume that the $\mathrm{Mn}$ and $\mathrm{Al}$ contents of RA are the equilibrium values at the annealing temperature of $700{ }^{\circ} \mathrm{C}$ since a long isothermal holding time was employed; in this case, we can compare the $\mathrm{C}$ contents of RA grains after different rolling processes. 


\section{Results}

\subsection{Microstructural Examination}

Figure 3 shows the examined microstructural evolutions of 7Mn steel from the different rolling processes to the final tensile fracture by EBSD. It can be seen that the hot rolled microstructures were composed of the as-quenched martensite and the equiaxed RA grains, the latter having the sub-micrometer size (Figure 3a1). During the subsequent IA treatment, new austenite grains were nucleated at the martensite lath boundaries and then they grew to a lath-like morphology together with the pre-existing RA grains; which led to most of ferrite and austenite grains having the lamellar morphology after IA (Figure 3a2). Figure 3b1 shows that the cold-rolled microstructures are composed of deformed ferrite and martensite. The latter was formed during the cold rolling due to strain-induced transformation so that it should have higher dislocation density than the as-quenched martensite. This can be confirmed by the deeper darkness in the image quality map due to the poor Kikuchi pattern quality resulting from high dislocation density. During the IA treatment, both the deformed ferrite and martensite grains recrystallized and some of them even transformed to austenite, resulting in the duplex $\gamma / \alpha$ grains having the equiaxed morphology, i.e., $\alpha_{G}+\gamma_{G}$ in Figure $3 b 2$. In contrast, the warm rolled microstructures are composed of both the lath-like martensite grains (Region ' $\mathrm{C}^{\prime}$ in Figure $3 \mathrm{c} 1$ ) and the equiaxed ferrite grains with the bimodal size distribution (Region ' $\mathrm{A}$ ' and ' $\mathrm{B}$ ') , which is consistent with our previous research [13]. When a new austenite grain was nucleated at the ultrafine and equiaxed ferrite grain boundaries, it grew to a fine size with the equiaxed morphology too, because the displacement of phase interface was determined by both the phase equilibrium between austenite and ferrite and the size of the parent ferrite grain. This is confirmed by the ' $\mathrm{A}$ ' region in Figure $3 \mathrm{c} 2$, in which both austenite and ferrite grains have equiaxed morphologies and sub-micrometer sizes. Moreover, the austenite grain nucleated at the coarse ferrite grain boundary could grow to a large size, as indicated by the ' $\mathrm{B}$ ' region in Figure 3c2. In addition to these equiaxed grains, we also found the lamellar $\gamma / \alpha$ grains after the IA treatment of warm-rolled structure, as shown in the ' $\mathrm{C}^{\prime}$ region of Figure $3 c 2$, whose formation mechanism should be same to the lamellar structure formed during the IA of hot-rolled steel. In other words, the warm-rolled structure is actually the mixture of hot-rolled and cold-rolled ones because it is composed of both lamellar and equiaxed $\gamma / \alpha$ grains. After fracture, most of RA grains in the annealed specimens have transformed to martensite, leading to the formation of triplex microstructures, i.e., ferrite, austenite and martensite. The remaining RA grains after fracture have ultrafine sizes in either equiaxed or lamellar morphologies, because the finer RA grains have higher mechanical stability than the coarser ones (Figure 3a3,b3,c3).

In addition to the $\gamma / \alpha$ duplex structures with both lamellar and equiaxed morphologies in the warm-rolled steel, a large amount of cementite particles was also observed within ferrite grains and at the ferrite grain boundaries, as shown in Figure 4a,b. Moreover, the cementite particles, which precipitated during warm rolling, did not dissolve completely during the IA at $700{ }^{\circ} \mathrm{C}$ for $5 \mathrm{~h}$ (Figure 4c,d); in contrast, no cementite was found when either the cold-rolled or hot-rolled 7Mn steel was annealed in the same way, see Figure $5 c, d$. This should be because very few carbide particles were formed during both hot rolling and cold rolling processes (Figure $5 a, b)$. Figure $4 \mathrm{e}, \mathrm{f}$ shows the TEM bright field images of microstructure after the IA of warm-rolled steel, which shows that the dislocation density in the lamellar $\gamma / \alpha$ grains is higher than that in the equiaxed ones, due to no occurrence of recrystallization in the lamellar grains during the IA; otherwise, the lamellar morphology should not remain. 

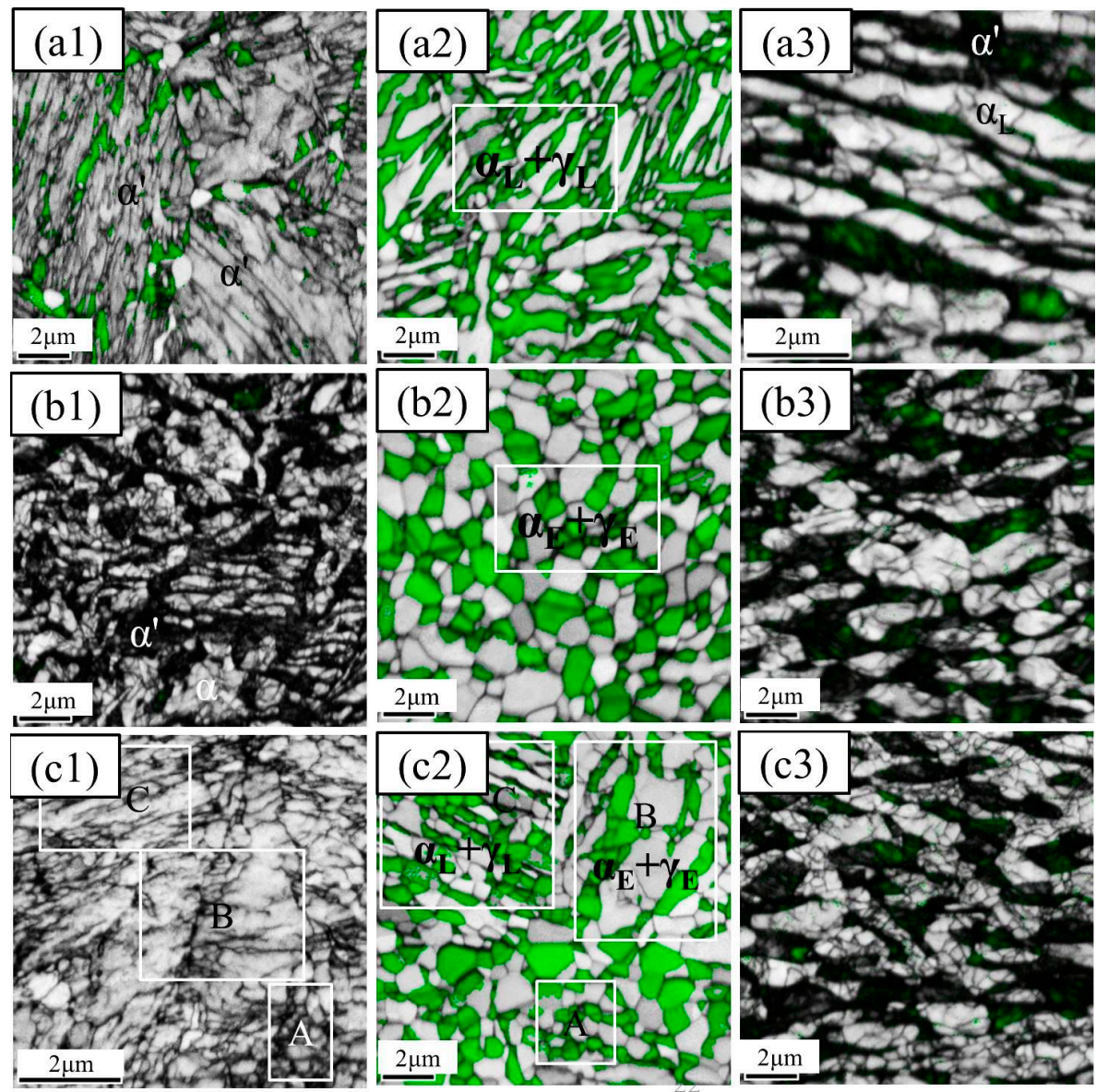

Figure 3. Electron backscatter diffraction (EBSD) band contrast images overlapped with phase distribution in the 7Mn steel subjected to different rolling processes. (a1) after HR; (b1) after CR; (c1) after WR; (a2) after HR + IA; (b2) after CR + IA; (c2) after WR + IA. (a3,b3,c3) are the microstructures after the tensile fracture of specimens subjected to the $\mathrm{HR}+\mathrm{IA}, \mathrm{CR}+\mathrm{IA}$ and $\mathrm{WR}+\mathrm{IA}$ processes respectively. $\mathrm{HR}, \mathrm{CR}, \mathrm{WR}$ and IA denote hot rolling, cold rolling, warm rolling and intercritical annealing. Austenite grains are in green color. The ' $\alpha_{\mathrm{L}}$ ' and ' $\gamma_{\mathrm{L}}$ ' represent lamellar ferrite and austenite; ' $\alpha_{\mathrm{E}}$ ' and ' $\gamma_{\mathrm{E}}$ ' represent the equiaxed ferrite and austenite; ' $\alpha$ ' denotes martensite.
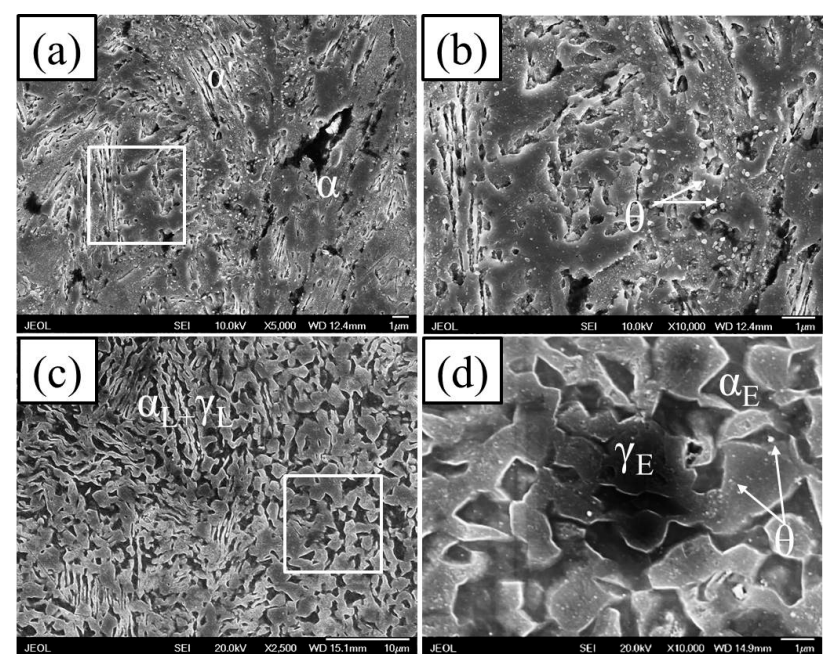

Figure 4. Cont. 


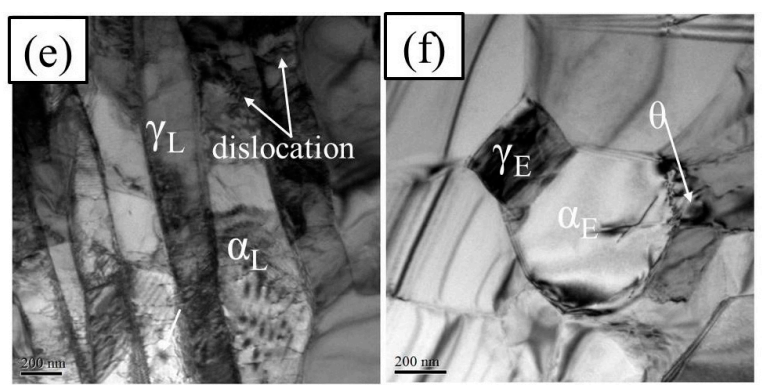

Figure 4. Field emission scanning electron microscope (FE-SEM) images of microstructures in the 7Mn steel after the warm rolling $(\mathbf{a}, \mathbf{b})$ and the intercritical annealing $(\mathbf{c}, \mathbf{d}) .(\mathbf{b}, \mathbf{d})$ are the magnified view of rectangle area in $(\mathbf{a}, \mathbf{c})$ respectively. $(\mathbf{e}, \mathbf{f})$ are the transmission-electron-microscope (TEM) bright field images showing high dislocation density only developed in the lamellar ferrite and austenite grains after warm rolling.

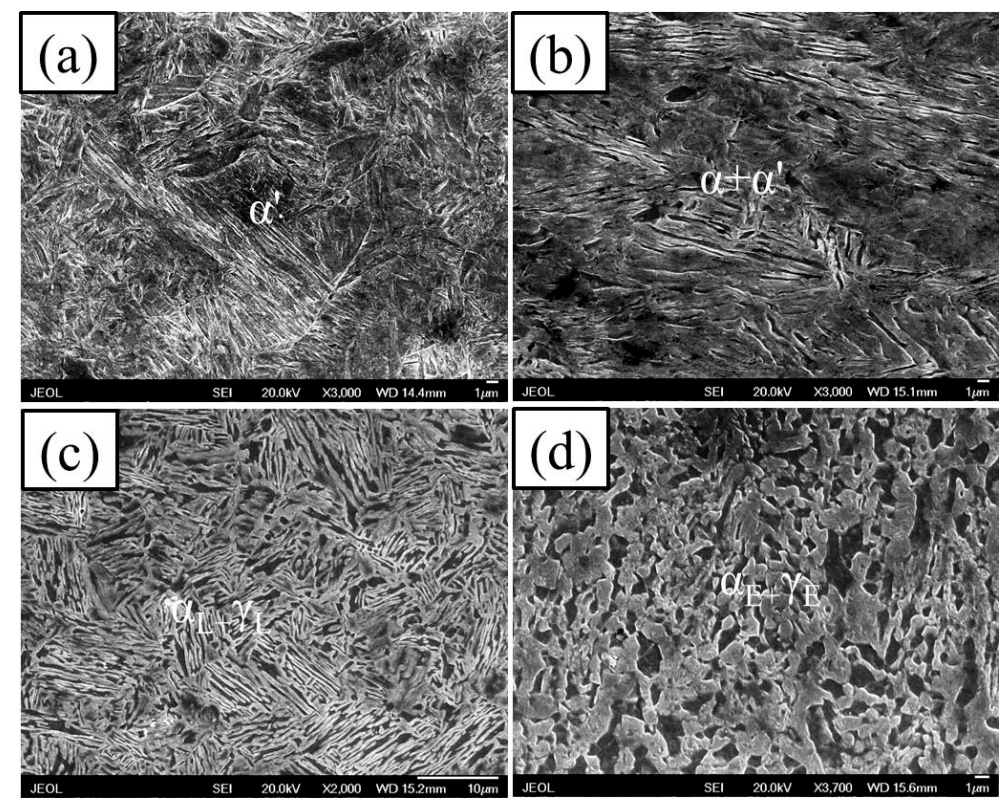

Figure 5. FE-SEM images of microstructures in 7Mn steel after the $H R$ (a) CR (b), HR + IA (c) and $\mathrm{CR}+\mathrm{IA}(\mathbf{d})$ processes. HR, CR, WR and IA denote hot rolling, cold rolling, warm rolling and intercritical annealing respectively.

\subsection{Mechanical Properties}

Table 1 shows the tensile properties of studied 7Mn steel after different rolling processes and the IA treatment, which were taken as the average values of two or three repeated measurements. The YS of warm-rolled and annealed steel is highest and that of cold-rolled one is lowest. Moreover, the warm rolled steel exhibits the best combination of UTS and TE. Both the warm-rolled and cold-rolled steels show the clear transition from the upper yielding point to the lower one, followed by yield point elongation (YPE) of about $2.8 \pm 0.9 \%$ and $4 \pm 0.6 \%$, respectively. In contrast, the hot rolled steel shows a continuous yielding (Figure 6a). In all the hot-rolled, cold-rolled and warm-rolled specimens, the stress serrations were seen at the different strains of $0.19 \pm 0.016,0.23 \pm 0.015$ and $0.30 \pm 0.037$ respectively (Figure $6 \mathrm{~b}-\mathrm{d}$ ). Some researchers attributed the stress serrations of medium $\mathrm{Mn}$ steels to the discontinuous TRIP effect [18]; however, this phenomenon could also be found in the high Mn TWIP steels, in which no martensitic transformation happened during the tensile deformation [19]. Furthermore, Huang et al. [20] systematically studied the kinematic and thermal aspects of the propagation of Portevin-Le Chatelier (PLC) band in 7Mn steel and found little austenite transformed 
during the propagation. Therefore, we infer that stress serrations might result from the commonly accepted mechanism, i.e., dynamic strain aging (DSA) [19]. Figure 6b through Figure $6 d$ show that the stress serrations on the stress-time curves are corresponding to the initiation of strain plateaus, which proves that the PLC band may periodically propagate out of the extensometer at the one end of tensile sample and then nucleate at the other end, producing the step-like serrations on the stress-strain curve. This has been observed in Reference [21] too.
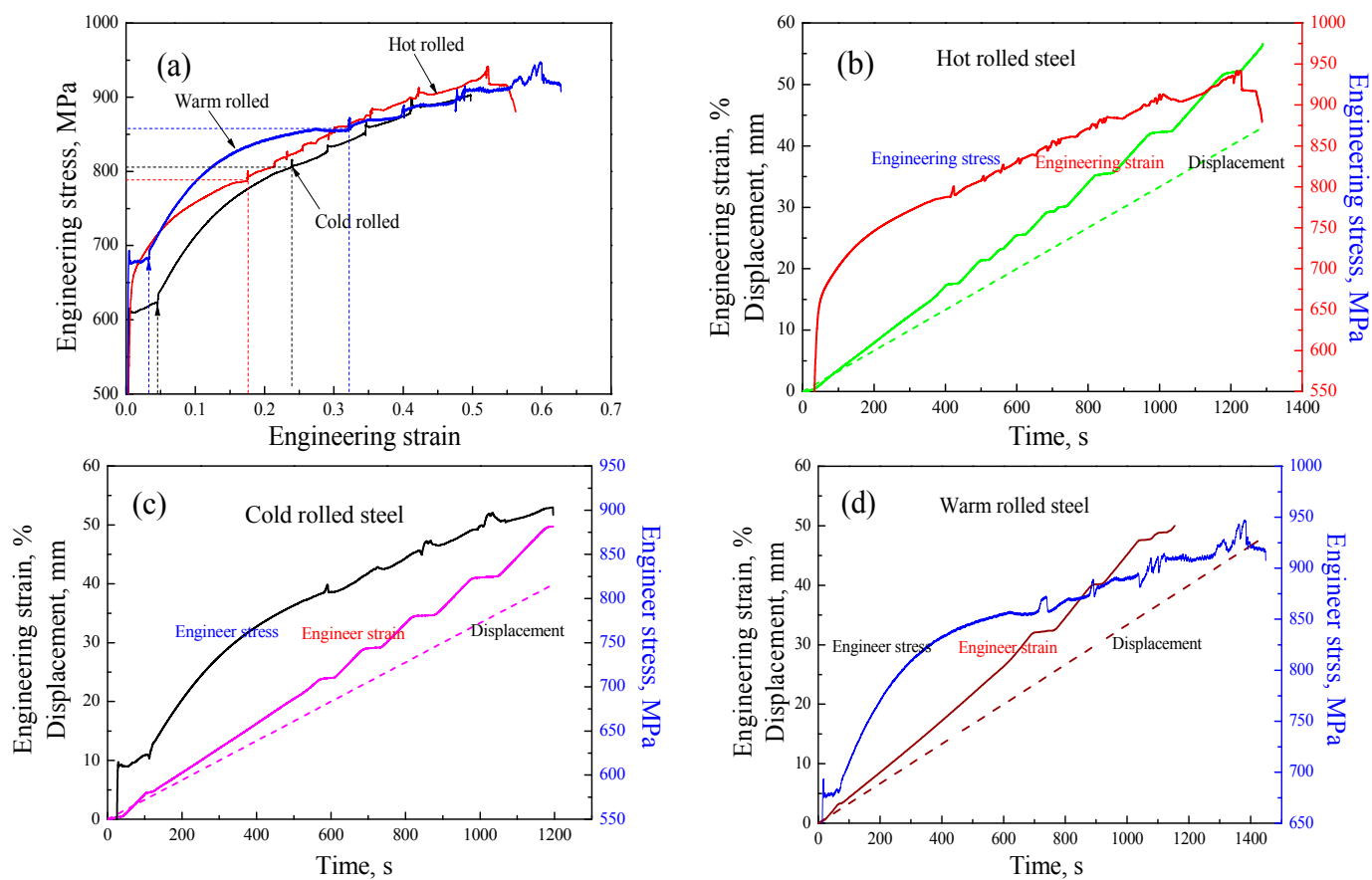

Figure 6. Tensile properties of studied 7Mn steel after the different rolling processes and subsequent IA treatment at $700{ }^{\circ} \mathrm{C}$ for $5 \mathrm{~h}$. (a) The engineering stress-strain curves for the specimens subjected to different rolling processes; the engineering stress/strain and the cross-head displacement varied with time during the tensile deformation for the specimen that was subjected to hot rolling (b), cold rolling (c) and warm rolling (d).

Table 1. Tensile properties of studied 7Mn steel after the different rolling processes and intercritical annealing treatment.

\begin{tabular}{cccccc}
\hline Rolling Processes & UTS/MPa & YS/MPa & TE/\% & YPE/\% & The Onset of DSA/\% \\
\hline Hot rolling & $937 \pm 5.8$ & $631 \pm 2.1$ & $58.4 \pm 3.7$ & & $19.0 \pm 1.6$ \\
Cold rolling & $910 \pm 56.6$ & $596 \pm 2.83$ & $42.1 \pm 10.8$ & $4.0 \pm 0.78$ & $23.5 \pm 0.6$ \\
Warm rolling & $943 \pm 7.8$ & $665 \pm 21.2$ & $61.9 \pm 1.3$ & $2.8 \pm 0.86$ & $29.7 \pm 3.7$ \\
\hline
\end{tabular}

\section{Discussion}

Lüders band is often observed during the tensile deformation of low carbon steels and other alloys. The solute interstitials such as $\mathrm{C}$ and $\mathrm{N}$ atoms are responsible for the formation of Lüders band by forming Cottrell atmosphere and locking dislocations [22-25]. The studied steels are multi-phased and composed of ferrite, austenite and even cementite in the warm rolled state. Lee et al. studied the tensile properties of both hot-rolled and cold-rolled medium-Mn steels and observed a continuous yielding in the hot rolled steel but discontinuous yielding in the cold rolled steel, which is exactly same to our result in Figure 6a. They concluded that the yielding behavior of multi-phased medium-Mn steel should be associated with the strain partition between different microstructure constitutes [11]. 
The microstructure of hot-rolled and annealed 7Mn steel is a mixture of lamellar ferrite $\left(\alpha_{\mathrm{L}}\right)$ and austenite $\left(\gamma_{\mathrm{L}}\right)$ grains, see Figures $3 \mathrm{a} 2$ and $5 \mathrm{c}$. Such lamellar morphology requires geometry-required dislocations well developed along the largest fraction of phase interface, leading to the deformation of two phases consistently without the formation of yielding plateau. In contrast, the microstructure of cold-rolled and annealed $7 \mathrm{Mn}$ steel is the mixture of equiaxed ferrite $\left(\alpha_{\mathrm{E}}\right)$ and austenite $\left(\gamma_{\mathrm{E}}\right)$ grains, see Figures $3 \mathrm{~b} 2$ and $5 \mathrm{~d}$. Because the severely deformed ferrite and martensite grains had recrystallized prior to the reverse transformation during the IA, both $\alpha_{\mathrm{E}}$ and $\gamma_{\mathrm{E}}$ grains had low density of dislocations due to active recovery and recrystallization. In this case, the $\alpha_{\mathrm{E}}$ grains, as the relatively soft phase, were easily deformed at the early stage of yielding; thus, Lüders band was formed and propagated by the interaction between mobile dislocations and the $C$ atoms in the $\alpha_{G}$ grains, resulting in the large YPE.

The warm-rolled and annealed microstructures are composed of both equiaxed and lamellar austenite and ferrite grains, a kind of mixture of both hot-rolled and cold-rolled structures, see Figures $3 \mathrm{c} 2$ and $4 \mathrm{c}$. In addition, the cementite particles were formed during warm rolling and they could not dissolve completely during the IA, see Figure 4a through Figure 4d. Thus, the remaining cementite particles could lead to a certain supersaturation of $C$ in the neighboring ferrite since the dissolving carbide particles should release the solute $\mathrm{C}$ atoms continuously. Both the fine cementite particles and supersaturated $C$ atoms could contribute to a significant increase of strength in ferrite by pinning and locking dislocations respectively, which may account for the highest YS observed in the warm-rolled and annealed specimen. Moreover, the warm-rolled and annealed specimen has the lower YPE than the cold-rolled one, which can be attributed to the following two reasons. One is that the fraction of equiaxed ferrite grains in the warm-rolled and annealed steel is smaller than that in the cold-rolled one because the former also includes some lamellar $\gamma / \alpha$ grains; the other is that the cementite particles remaining after the IA may strengthen ferrite, which leads to the reduced difference between the strength of equiaxed ferrite and austenite grains. As a consequence, the relatively coarse equiaxed ferrite grains in the warm-rolled and annealed specimen were first yielded but with a short Lüders strain.

The flow stress serration occurred at the lowest values of strain and stress in the hot-rolled and annealed steel among three studied steels. This is because the $C$ content of austenite in the hot-rolled specimen is highest (see Figure 7) because both the high dislocation density and the shortest diffusion distance in the lamellar duplex structure could accelerate the $\mathrm{C} / \mathrm{Mn}$ partition between ferrite and austenite. In contrast, the average $C$ content of RA grains in the warm-rolled steel is lowest due to the existence of un-dissolved cementite particles (Figure 4d). Therefore, the highest solute $\mathrm{C}$ content may result in the DSA effect to initiate at the smallest strain/stress levels while the lowest $C$ content of austenite corresponds to most delayed flow serration.

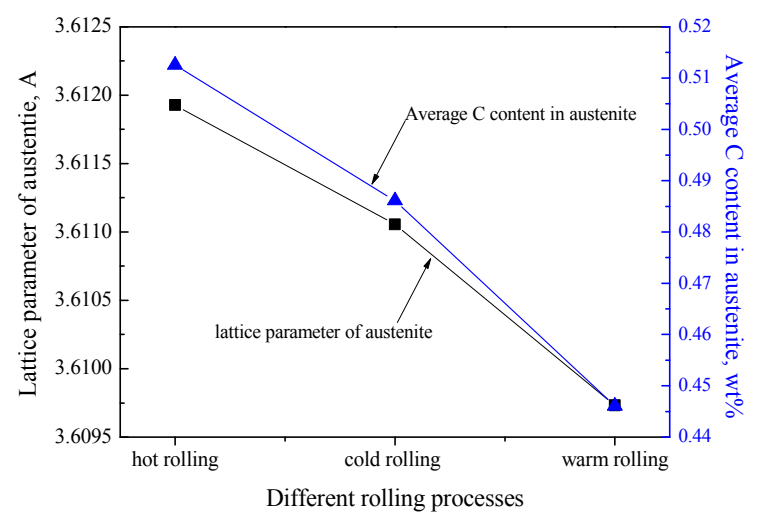

Figure 7. The average lattice parameters and $C$ contents of retained austenite (RA) grains from the XRD measurements on the studied 7Mn steel, which was subjected to different rolling processes and the intercritical annealing at $700{ }^{\circ} \mathrm{C}$ for $5 \mathrm{~h}$. 
Figure 8 shows how many fractions of RA grains have transformed during the tensile deformation of 7Mn steel that was subjected to different rolling processes. It is noticed that the RA fractions after the IA are very close to the equilibrium value at $700{ }^{\circ} \mathrm{C}$ (Figure 1a), indicating that the assumption of calculating the average $\mathrm{C}$ content of austenite under equilibrium is reasonable. The largest fraction of RA transformed during the tensile deformation of warm-rolled steel, which could make the most contribution to work hardening via the largest TRIP effect. This may be attributed to the RA grains in the warm rolled steel having two different morphologies and much wide size distribution so that they can have a wider range of mechanical stability than those in both cold-rolled and hot-rolled specimens; therefore, they could transform in a more successive way during deformation, which contributes to a more sustainable work hardening and then leads to the highest combination of UTS and TE.

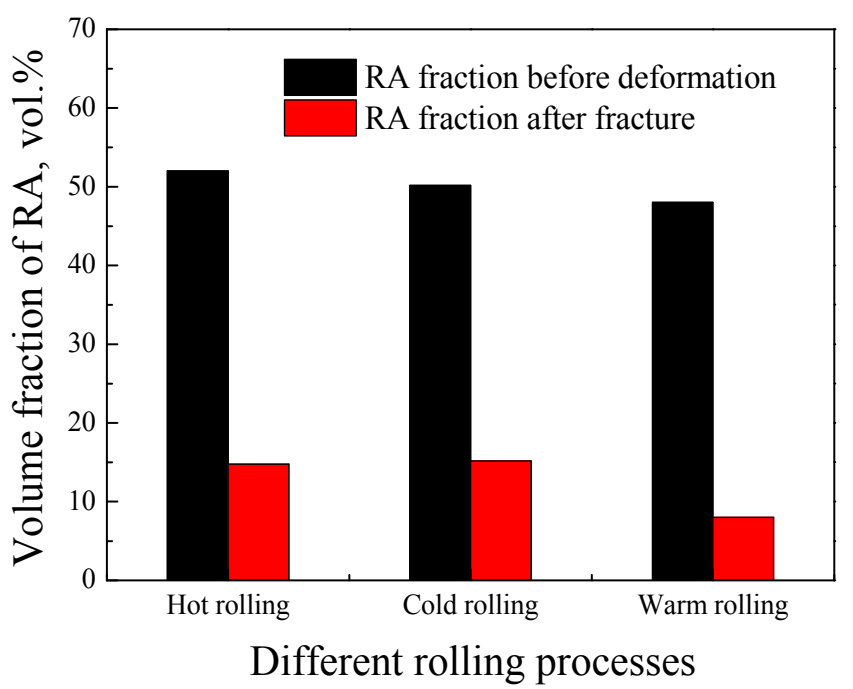

Figure 8. Variations of RA fraction before and after the tensile deformation in the specimens subjected to different rolling processes and the intercritical annealing at $700{ }^{\circ} \mathrm{C}$ for $5 \mathrm{~h}$.

\section{Conclusions}

In this paper, we studied the microstructures and mechanical properties of 7Mn steel, which was either hot rolled, warm rolled or cold rolled and finally all intercritically annealed at $700{ }^{\circ} \mathrm{C}$ for $5 \mathrm{~h}$. The following conclusions can be drawn:

1. The hot-rolled and annealed microstructures are mostly composed of lamellar austenite and ferrite grains; whilst the cold-rolled ones composed of equiaxed austenite and ferrite grains. In contrast, the warm-rolled and annealed microstructures are the mixture of hot-rolled and cold-rolled ones because the warm rolling produces both martensite and some equiaxed ferrite grains, which then transform to lamellar and equiaxed austenite grains during the IA, respectively. As a result, the warm rolling and IA process leads to $\gamma / \alpha$ grains having both lamellar and equiaxed morphologies.

2. Among the three studied steels, the largest fraction of RA grains transformed to martensite during the deformation of warm-rolled and annealed steel, leading to the best combination of UTS and TE. This is due to the RA grains in the warm-rolled and annealed steel having two different morphologies and a wide size distribution, which may result in a more sustainable transformation during deformation than that in hot-rolled and cold-rolled ones.

3. The warm rolling process also leads to the extensive precipitation of cementite, which could not dissolve completely during the subsequent IA at $700{ }^{\circ} \mathrm{C}$ for $5 \mathrm{~h}$. The remaining cementite particles may strengthen the coarse ferrite grains, resulting in the highest YS observed in the warm-rolled and annealed steel. 
4. The hot-rolled and annealed steel exhibits continuous yielding during the tensile deformation; in contrast, the cold-rolled and warm-rolled ones both exhibit discontinuous yielding. The yield point elongation of warm-rolled and annealed steel is smaller because the fraction of relatively coarse and equiaxed ferrite grains is smaller and strengthened by the un-dissolved carbide particles with fine size.

Acknowledgments: The authors acknowledge the Fundamental Research Funds for the Central Universities and the joint financial support from National Natural Science Foundation of China and Bao Steel Group Co. Ltd. (No. U1460203), the latter is located in Shanghai, China. The authors thank YuanShen Zhu, PengYu Wen and XiaoHui Wang for their help on the experiment.

Author Contributions: H.W.L. designed and supervised the research and revised the manuscript; B.H. performed the experiments and analyzed the data and wrote the paper.

Conflicts of Interest: The authors declare no conflict of interest.

\section{References}

1. Lee, Y.K.; Han, J. Current opinion in medium manganese steel. Mater. Sci. Technol. 2015, 31, $843-856$. [CrossRef]

2. Suh, D.W.; Kim, S.J. Medium Mn transformation-induced plasticity steels: Recent progress and challenges. Scr. Mater. 2017, 126, 63-67. [CrossRef]

3. Cao, W.Q.; Wang, C.; Shi, J.; Wang, M.Q.; Hui, W.J.; Dong, H. Microstructure and mechanical properties of Fe-0.2C-5Mn steel processed by ART-annealing. Mater. Sci. Eng. A 2011, 528, 6661-6666. [CrossRef]

4. Shi, J.; Sun, X.J.; Wang, M.Q.; Hui, W.J.; Dong, H.; Cao, W.Q. Microstructure and mechanical properties of Fe-0.2C-5Mn steel processed by ART-annealing. Scr. Mater. 2010, 63, 815-818. [CrossRef]

5. Xu, H.F.; Zhao, J.; Cao, W.Q.; Shi, J.; Wang, C.Y.; Wang, C.; Li, J.; Dong, H. Heat treatment effects on the microstructure and mechanical properties of a medium manganese steel (0.2C-5Mn). Mater. Sci. Eng. A 2012, 532, 435-442. [CrossRef]

6. Wang, C.; Shi, J.; Wang, C.Y.; Wang, M.Q.; Dong, H.; Cao, W.Q. Development of ultrafine lamellar ferrite and austenite duplex structure in 0.2C5Mn steel during ART-annealing. ISIJ Int. 2011, 51, 651-656. [CrossRef]

7. Zhao, C.; Cao, W.Q.; Zhang, C.; Yang, Z.G.; Dong, H.; Weng, Y.Q. Effect of annealing temperature and time on microstructure evolution of $0 \cdot 2 \mathrm{C}-5 \mathrm{Mn}$ steel during intercritical annealing process. Mater. Sci. Technol. 2014, 30, 791-799. [CrossRef]

8. Gibbs, P.J.; Moor, E.D.; Merwin, M.J.; Clausen, B.; Speer, J.G.; Matlock, D.K. Austenite stability effects on tensile behavior of manganese-enriched-austenite transformation-induced plasticity steel. Metall. Mater. Trans. A 2011, 42, 3691-3702. [CrossRef]

9. Aydin, H.; Jung, I.-H.; Essadiqi, E.; Yue, S. Twinning and Tripping in 10\% Mn steels. Mater. Sci. Eng. A 2014, 591, 90-96. [CrossRef]

10. Suh, D.W.; Park, S.J.; Lee, T.H.; Oh, C.S.; Kim, S.J. Influence of al on microstructure and mechanical behavior of cr-containing transformation-induced plasticity steel. Metall. Mater. Trans. A 2010, 41, 397-408. [CrossRef]

11. Han, J.; Lee, S.J.; Jung, J.G.; Lee, Y.K. The effects of the initial martensite microstructure on the microstructure and tensile properties of intercritically annealed Fe-9Mn-0.05 C steel. Acta Mater. 2014, 78, 369-377. [CrossRef]

12. Luo, H.W.; Qiu, C.H.; Dong, H.; Shi, J. Experimental and numerical analysis of influence of carbide on austenitisation kinetics in 5Mn TRIP steel. Mater. Sci. Technol. 2014, 30, 1367-1377. [CrossRef]

13. Hu, B.; Luo, H.W. A strong and ductile $7 \mathrm{Mn}$ steel manufactured by warm rolling and exhibiting both transformation and twinning induced plasticity. J. Alloys Compd. 2017, 725, 684-693. [CrossRef]

14. Hu, B.; Luo, H.W.; Yang, F.; Dong, H. Recent progress in medium-Mn steels made with new designing strategies, a review. Mater. Sci. Technol. 2017. [CrossRef]

15. Saleh, M.H.; Priestner, R. Retained austenite in dual-phase silicon steels and its effect on mechanical properties. J. Mater. Process. Technol. 2001, 113, 587-593. [CrossRef]

16. BabU, S.S.; Specht, E.D.; David, S.A.; Karapetrova, E.; Zschack, P.; Peet, M.; Bhadeshia, H.K.D.H. In-situ observations of lattice parameter fluctuations in austenite and transformation to bainite. Metall. Mater. Trans. A 2005, 36, 3281-3289. [CrossRef] 
17. Sohn, S.S.; Song, H.; Suh, B.C.; Kwak, J.H.; Lee, B.J.; Kim, N.J.; Lee, S. Novel ultra-high-strength (ferrite + austenite) duplex lightweight steels achieved by fine dislocation substructures (Taylor lattices), grain refinement, and partial recrystallization. Acta Mater. 2015, 96, 301-310. [CrossRef]

18. Cai, Z.H.; Ding, H.; Misra, R.D.K.; Ying, Z.Y. Austenite stability and deformation behavior in a cold-rolled transformation-induced plasticity steel with medium manganese content. Acta Mater. 2015, 84, 229-236. [CrossRef]

19. Bouaziz, O.; Allain, S.; Scott, C.P.; Cugy, P.; Barbier, D. High manganese austenitic twinning induced plasticity steels: A review of the microstructure properties relationships. Curr. Opin. Solid State Mater. Sci. 2011, 15, 141-168. [CrossRef]

20. Wang, X.G.; Wang, L.; Huang, M.X. Kinematic and thermal characteristics of Lüders and Portevin-Le Châtelier bands in a medium Mn transformation-induced plasticity steel. Acta Mater. 2017, 124, 17-29. [CrossRef]

21. Lee, S.; Kim, J.; Lee, S.J.; de Cooman, B.C. Effect of nitrogen on the critical strain for dynamic strain aging in high-manganese twinning-induced plasticity steel. Scr. Mater. 2011, 65, 528-531. [CrossRef]

22. Hall, E.O. The deformation and ageing of mild steel: III discussion of results. Proc. Phys. Soc. Sect. B 1951, 64, 742-747. [CrossRef]

23. Luo, H.; Dong, H.; Huang, M.X. Effect of intercritical annealing on the Lüders strains of medium Mn transformation-induced plasticity steels. Mater. Des. 2015, 83, 42-48. [CrossRef]

24. Emadoddin, E.; Akbarzadeh, A.; Daneshi, G.H. Correlation between Luder strain and retained austenite in TRIP-assisted cold rolled steel sheets. Mater. Sci. Eng. A 2007, 447, 174-179. [CrossRef]

25. Lloyd, D.J.; Morris, L.R. Luders band deformation in a fine grained aluminium alloy. Acta Metall. 1977, 25, 857-861. [CrossRef]

(C) 2017 by the authors. Licensee MDPI, Basel, Switzerland. This article is an open access article distributed under the terms and conditions of the Creative Commons Attribution (CC BY) license (http:/ / creativecommons.org/licenses/by/4.0/). 